OPEN ACCESS

Edited by:

Lei Chen,

Tianjin University, China

Reviewed by: Abdul Munir Abdul Murad, Universiti Kebangsaan Malaysia,

Malaysia

Michael Benedik, Texas A\&M University, United States

*Correspondence: Haijin Mou mousun@ouc.edu.cn Zhemin Liu ocean2013@126.com

Specialty section:

This article was submitted to Microbiotechnology,

a section of the journal

Frontiers in Microbiology

Received: 08 June 2021 Accepted: 05 August 2021 Published: 01 September 2021

Citation: Liang Q, Zhan Y, Yuan M, Cao L,

Zhu C, Mou H and Liu Z (2021) Improvement of the Catalytic Ability of a Thermostable and Acidophilic $\beta$-Mannanase Using a Consensus Sequence Design Strategy.

Front. Microbiol. 12:722347. doi: 10.3389/fmicb.2021.722347

\section{Improvement of the Catalytic Ability of a Thermostable and Acidophilic $\beta$-Mannanase Using a Consensus Sequence Design Strategy}

\author{
Qingping Liang1, Yuming Zhan², Mingxue Yuan ${ }^{1}$, Linyuan Cao', Changliang Zhu', \\ Haijin $\mathrm{Mou}^{1 *}$ and Zhemin Liu ${ }^{1 *}$ \\ ${ }^{1}$ College of Food Science and Engineering, Ocean University of China, Qingdao, China, ${ }^{2}$ Shandong Provincial Key \\ Laboratory of Quality Safety Monitoring and Risk Assessment for Animal Products, Jinan, China
}

In order to improve the catalytic efficiency of a thermostable and acidophilic $\beta$-mannanase (ManAK; derived from marine Aspergillus kawachii IFO 4308), three mutants were designed by amino acid sequence consensus analysis with a second $\beta$-mannanase (ManCbs), which also belongs to the glycoside hydrolase family 5 (GH5) and has excellent catalytic efficiency. Three mutants were constructed and their biochemical characteristics were measured after heterologous expression in Pichia pastoris. The results revealed that the $\mathrm{K}_{\mathrm{cat}} / \mathrm{K}_{\mathrm{m}}$ values of the three recombinant mannanases ManAK ${ }^{\mathrm{C} 292 \mathrm{~V}}$, ManAK ${ }^{\mathrm{L} 293 \mathrm{~V}}$, and ManAK ${ }^{\mathrm{L} 294 \mathrm{H}}$ were enhanced by 303.0, 280.4, and $210.1 \%$, respectively. Furthermore, ManAK ${ }^{\text {L293V }}$ showed greater thermostability than ManAK, retaining $36.5 \%$ of the initial enzyme activity after incubation at $80^{\circ} \mathrm{C}$ for $5 \mathrm{~min}$. This study therefore provides a rational design strategy based on consensus sequence analysis to develop industrially valuable $\beta$-mannanase for future applications in marine aquafeed.

Keywords: $\beta$-mannanase, consensus sequence design, catalytic ability, thermostability, rational design

\section{INTRODUCTION}

$\beta$-Mannanases are endo-hydrolases, which can hydrolyze mannan to small molecular degradation products (Chauhan et al., 2012; Finn et al., 2014; Srivastava and Kapoor, 2017). They have been used as food stabilizers, bleaching agents in papermaking, and washing and cleaning agents (Kaira et al., 2016). They are also added into fish feedstuffs (such as soybean meal) to improve the nutritional value (Cai et al., 2011), and can significantly reduce the viscosity of coffee extract to reduce the energy consumption of large-scale coffee production (Chauhan et al., 2014a). Furthermore, manno-oligosaccharides (MOS), which are regarded as potential novel prebiotics, and are added into aquafeed, can be prepared by hydrolysis with $\beta$-mannanases (Jana et al., 2020). Therefore, improved enzymatic properties of $\beta$-mannanases, such as thermal stability, acid tolerance, and high catalytic ability would be desirable.

In our previous work, a $\beta$-mannanase (ManAK) derived from marine Aspergillus kawachii IFO 4308 was heterologously expressed in Pichia pastoris (Liu et al., 2020b). ManAK is a thermostable and acidophilic enzyme, with an optimal catalytic temperature of $80^{\circ} \mathrm{C}$ and $\mathrm{pH}$ optimum of 2.0. This characteristic makes ManAK a valuable enzyme in MOS preparation 
from plant gums [e.g., konjac gum, locust bean gum (LBG), and guar gum], because both high temperature and acidic conditions could decrease the stickiness of the substances and accelerate enzymatic hydrolysis (Zheng et al., 2018; La Rosa et al., 2019). However, the low catalytic efficiency of ManAK has restricted the economic production of MOS. Therefore, improvement of the catalytic efficiency of ManAK without impairing its innate thermostability and acid tolerance is meaningful.

Consensus sequence design (CSD) strategy offers a promising solution for designing enzymes of evaluated catalytic efficiency, while retaining other original properties (Sternke et al., 2019). Since the amino acid sequence of the catalytic region is generally recognized as one of the most important factors affecting the catalytic efficiency of enzymes, amino acids in the catalytic region are normally selected as the mutation targets to improve the catalytic efficiency of enzymes. Ratananikom et al. (2013), for example, reported that two $\beta$-glucosidases (Dalcochinase and $\mathrm{Abg}$ ) had different levels of catalytic efficiency toward glycone substrates, and believed that it might be caused by the difference in amino acid residues around the glycobasebinding region. Based on this, three mutants of dalcochinase were constructed (F196H, S251V, and M369E), and the catalytic efficiency was shown to have been significantly improved. However, this CSD strategy has rarely been used to improve the catalytic efficiency of $\beta$-mannanases.

According to the classification of the carbohydrate activity database, ${ }^{1}$ ManAK is in the GH5 family (Larsson et al., 2006; van Zyl et al., 2010; Liu et al., 2020b). $\beta$-mannanases of this family share a similar $(\beta / \alpha)_{8}$-folded barrel structure and catalyze the reaction by complying with the double substitution reaction mechanism (Hilge et al., 1998; Zhang et al., 2008). ManCbs, derived from the fibrolytic bacterium Cellulosimicrobium sp. strain HY-13, is a neutral-type mannanase in the same family, but has much higher catalytic activity than ManAK. The specific activity of ManCbs can be as high as $14,711 \mathrm{IU} \mathrm{mg} \mathrm{mg}^{-1}$ (Kim et al., 2011), which is greater than that of ManAK. Considering that ManAK and ManCbs share high sequence similarity (86.4\%) in the catalytic region, it is theoretically feasible to enhance the catalytic efficiency of ManAK according to CSD strategy.

In this study, the CSD strategy was adopted to rationally design potential enzyme mutants with elevated catalytic efficiency. Three recombinant ManAK mutants were heterologously expressed by $P$. pastoris. The recombinant enzymes were purified, and their enzymatic properties were fully assayed. Changes in enzymatic properties were illustrated in terms of the structurefunction relationship by analyzing the alterations in non-covalent bond interactions between ManAK and its mutants.

\section{MATERIALS AND METHODS}

\section{Materials}

Thermostable and acidophilic $\beta$-mannanase was purified from A. kawachii IFO 4308 (BioProject accession: PRJDA66971), and the coding sequence was derived from the gene sequence published by NCBI with the GenBank accession No.: GAA89125.1 as previously reported (Liu et al., 2020b). The Escherichia coli DH5 $\alpha$ and the P. pastoris X33 (Invitrogen, United States) were purchased from Sigma-Aldrich (St. Louis, MO, United States). These strains were used to prepare expression plasmids and as expression hosts, respectively. All chemicals and reagents used were purchased from Sigma-Aldrich (St. Louis, MO, United States) and of analytical grade.

\section{Alignment Analysis of Gene Sequences of ManAK and ManCbs}

Thermostable and acidophilic $\beta$-mannanase and ManCbs belong to the GH5 family, and the two gene sequences are highly conserved and homologous. The tertiary structure of ManAK was automatically modeled by the Phyre 2 program ${ }^{2}$ based on the reported crystal structure of ManBK (PDB code: 3WH9; 95\% identity), and the tertiary structures of ManCbs were modeled by the same way. Sequence alignment and structure analysis were performed by Discovery Studio 2.5 software (Accelrys, San Diego, CA, United States). Figure rendering was performed by PyMOL software (version 1.7.2; Delano Scientific, United States).

\section{Construction of Recombinant Expression Plasmids of ManAK}

Three mutants (ManAK ${ }^{\mathrm{C} 292 \mathrm{~V}}$, ManAK ${ }^{\mathrm{L} 293 \mathrm{~V}}$, and $\mathrm{ManAK}^{\mathrm{L} 294 \mathrm{H}}$ ) were created based on the amino acid sequence consensus analysis between ManAK and ManCbs. Vector NTI 13.5 was used to design and analyze the PCR mutation primers according to the rational design sequence of ManAK. To insert the mutated gene into the expression vector $\mathrm{pPICZ} \alpha \mathrm{A}$, all primers had homology arm sequences at both ends of the vector insertion site (Table 1). The $\mathrm{T}_{\mathrm{m}}$ values of all primers were approximately $60^{\circ} \mathrm{C}$, and $\mathrm{GC} \%$ was kept below $60 \%$. Both primers were synthesized by the Ruibo Xingke Company, Beijing.

pPICZ $\alpha$ A-AK was constructed by ligating the original ManAK gene (GenBank accession No.: GAA89125.1) into the pPICZ $\alpha$ A expression plasmid, and the integrated vector was transformed into E. coli $\mathrm{DH} 5 \alpha$, which was considered as the template for the preparation of the other three recombinant expression plasmids. Synthetic primers were used to amplify the three mutant enzyme genes by PCR reaction according to the Mut Express ${ }^{\circledR}$ II kit instructions. The three recombinant expression plasmids were constructed by homologous recombination of the genes prepared with the pPICZ $\alpha$ A expression plasmid; named pPICZ $\alpha$ A-ManAK ${ }^{\mathrm{C} 292 \mathrm{~V}}, \mathrm{pPICZ} \alpha$ $\mathrm{A}-\mathrm{ManAK}^{\mathrm{L} 293 \mathrm{~V}}$, and $\mathrm{pPICZ} \alpha \mathrm{A}-\mathrm{ManAK}^{\mathrm{L} 294 \mathrm{H}}$.

\section{Heterologous Expression of Recombinant Mutants in $P$. pastoris and Purification}

The recombinant expression plasmids pPICz $\alpha$ A-ManAK ${ }^{\mathrm{C} 292 \mathrm{~V}}$, pPICz $\alpha$ A-ManAK ${ }^{\mathrm{L} 293 \mathrm{~V}}$, and pPICz $\alpha$ A-ManAK ${ }^{\mathrm{L} 294 \mathrm{H}}$ were 
TABLE 1 | Primers used for site-directed mutagenesis.

\begin{tabular}{|c|c|}
\hline Mutants & Primers \\
\hline ManAK ${ }^{\mathrm{C} 292 \mathrm{~V}}$ & $\begin{array}{l}\text { Reverse: 5'-TGGTAAGCCAGTITGTTGGAAGAATACGGTGTTACTTCTAACCAT-3' } \\
\text { Forward: 5'-CTTCCAACAAAACTGGCTTACCAGCAGCCTTACAAGC-3' }\end{array}$ \\
\hline ManAK ${ }^{\mathrm{L} 294 \mathrm{H}}$ & $\begin{array}{l}\text { Reverse: 5'-TAAGCCATGTGTITGGAAGAATACGGTGTTACTTCTAACCATTG-3' } \\
\text { Forward: 5'-ATTCTTCCAAAACACATGGCTTACCAGCAGCCTTACAAG-3' }\end{array}$ \\
\hline ManAK ${ }^{\mathrm{L294H}}$ & $\begin{array}{l}\text { Reverse: 5'-GCCATGTTTGGATGAAGAATACGGTGTTACTTCTAACCATTGTTCT-3' } \\
\text { Forward: 5'-CGTATTCTTCATCCAAACATGGCTTACCAGCAGCCTTAC-3' }\end{array}$ \\
\hline
\end{tabular}

linearized and digested with Sal I enzyme, and transformed into $P$. pastoris $\mathrm{X} 33$ by electroporation. The transformed colonies were grown on YPD solid plates containing $100 \mu \mathrm{g} /$ $\mathrm{ml}$ Zeocin (Thermo Scientific) and incubated at $30^{\circ} \mathrm{C}$ for 5 days. Colonies were then transferred to Buffered Minimal Glycerol-complex Medium, and $1.0 \%(\mathrm{v} / \mathrm{v})$ methanol was added to induce protein expression. The cultures were incubated in a shaker at $30^{\circ} \mathrm{C}$ for 3 days to allow secretion of the expression product. Supernatant was collected and concentrated by ultrafiltration with a $50 \mathrm{kDa}$ membrane. The sample was then loaded onto a Ni-Sepharose 6FF column (GE Healthcare, United States), and the sample eluted according to the method described by Zhang et al. (2019). The sample was dialyzed against $50 \mathrm{mM}$ potassium phosphate buffer ( $\mathrm{pH}$ 5.5) and analyzed by SDS-PAGE gel chromatography. The concentration of the purified enzyme solution was determined by the Bradford method (Bradford, 1976).

\section{Biochemical Characterization of Recombinant ManAK ${ }^{\mathrm{C} 292 \mathrm{~V}}$ and ManAK ${ }^{\mathrm{L} 293 \mathrm{~V}}$ and ManAK ${ }^{\mathrm{L} 294 \mathrm{H}}$}

To assess the effects of the site directed mutagenesis, the biochemical characteristics of the recombinant enzymes were measured. The enzymatic activity of mannanases was determined using the 3,5-dinitrosalicylic acid (DNS) method: the expressed enzyme solution was diluted with $50 \mathrm{mM}$ sodium acetate buffer, and reacted with an equal volume of $0.5 \%(\mathrm{w} / \mathrm{v}) \mathrm{D}$-mannan (Sigma, St. Louis, MO, United States) at $37^{\circ} \mathrm{C}$ for $30 \mathrm{~min}$. The D-mannan used here was LBG (Sigma), which was dissolved in boiling sodium acetate buffer, and then diluted to $100 \mathrm{ml}$ to prepare the substrate. Subsequently, DNS reagent was added and the reaction incubated in a boiling water bath for $5 \mathrm{~min}$, and then the optical density measured at $540 \mathrm{~nm}$ (Miller, 1959). One unit (U) of mannanase activity is defined as the amount of enzyme needed to generate $1 \mu \mathrm{mol}$ of reducing sugar/minute at $\mathrm{pH} 5.5$ and $37^{\circ} \mathrm{C}$ from a solution of $3 \mathrm{mg} / \mathrm{ml}$ mannan.

The optimal temperature for activity of the mannanases was determined by comparing the relative enzyme activity of the sample at a range of temperatures between 35 and $85^{\circ} \mathrm{C}$ (in $50 \mathrm{mM}$ sodium acetate buffer, $\mathrm{pH}$ 5.5). The mixture samples of enzymes and substrate were reacted at various temperatures for $5 \mathrm{~min}$ to access the recombinant mannanase activity. In addition, the thermal stability of the enzymes was determined after preincubation of enzymes without substrate in $50 \mathrm{mM}$ sodium acetate buffer $(\mathrm{pH} 5.5)$ at different temperatures $(60,70$, and $80^{\circ} \mathrm{C}$ ) for different times $(5,10,15,20$, and $25 \mathrm{~min}$ ). After this thermal treatment, the enzymes were mixed with substrate and reacted under standard conditions $\left(\mathrm{pH} 5.5,37^{\circ} \mathrm{C}\right.$, and $30 \mathrm{~min}$ ) to obtain the residual rate of enzyme activity after heat treatment.

Dilute mannanase enzyme solution was tested with the different $\mathrm{pH}$ buffers (i) Glycine- $\mathrm{HCl}(\mathrm{pH} 1.0-4.0)$, (ii) sodium acetate buffer ( $\mathrm{pH}$ 4.0-6.0), and (iii) Tris-HCl buffer $(\mathrm{pH}$ $6.0-8.0)$. Using the $0.5 \%(\mathrm{w} / \mathrm{v})$ LBG under different $\mathrm{pH}$ conditions (1.0-8.0) as substrates, the optimal $\mathrm{pH}$ of recombinant mannanases was determined under standard conditions $\left(37^{\circ} \mathrm{C}\right.$, $30 \mathrm{~min})$. After the sample was treated with a buffer of the same $\mathrm{pH}$ value range $(1.0-8.0)$ at $37^{\circ} \mathrm{C}$ for $2 \mathrm{~h}$, the residual rate of enzyme activity was measured according to the same method to obtain the $\mathrm{pH}$ stability.

To obtain the kinetic characteristics of the mannanase samples, the enzyme activity was measured under standard conditions using $1-10 \mathrm{mg} / \mathrm{ml}$ LBG as a substrate. The data were analyzed by Origin 8.5 software and the dynamic parameters $\mathrm{K}_{\mathrm{m}}$ and $\mathrm{k}_{\mathrm{cat}}$ were obtained. Dynamic curves were drawn according to the nonlinear regression method.

The three-dimensional structures of ManAK and recombinant mutants were modeled by the Phyre2 website (see Footnote 2; Kelley et al., 2016). Using Auto Dock Tools 1.5.6, the three recombinant samples were docked by molecular simulation and compared. The differences between the structure of the native ManAK and the modified versions around the mutated sites were then obtained. The software used in the molecular visualization and graphics drawing process was PyML (v1.7.2; Delano Scientific, United States), and Discovery Studio 2.5 software was used to make a simulated two-dimensional diagram of the interaction force between molecules.

\section{Analysis of Hydrolysis Products}

In order to understand and compare the degradation efficiency and mode of action of ManAK and its mutant forms, the hydrolysis products of the mannobiose (M2), mannotriose (M3), mannotetraose (M4), and mannopentaose (M5) standard of MOS were analyzed using the ManAK ${ }^{\mathrm{L} 293 \mathrm{~V}}$ mutant. The reaction was carried out at $37^{\circ} \mathrm{C}$ for $10 \mathrm{~min}$ for all MOS, and the reactants were $5 \mathrm{U}$ purified enzyme and $20 \mathrm{mM}$ MOS standard solution. The reaction was terminated by boiling the sample in water for $10 \mathrm{~min}$, then the macromolecules were removed using a $3-\mathrm{kDa}$ Millipore membrane (Millipore, United States) for ultrafiltration. After centrifugation at $13,000 \mathrm{~g}$ for $10 \mathrm{~min}$, 
A

ManAK

ManCbs

ManAK

ManCbs

ManAK ManCbs

ManAK

ManCbs

ManAK ManCbs

ManAK ManCbs

ManAK

ManCbs

(1) LPRASPAPSSSSSSSSASTSFASTSGLQFTIDETGYEAGFNSYWIGFITDDSDVDLVMSHLRS ------APSRAVQARLNAGFVMVEDGRFRLDGRDFHFAGSNAYYFPFNGGQDDVERGLMAAKN

(66) SGLRILRVWGFNDVT-TQPSSGTVWYQLHQDGRSTI--------NTGADGIQRLDYVVSSAEQHD AGLTVFRTWGFNDRNVTYVPGGLPQYGGEGAGPSEVVEQWWHDNGTSTIDVTGFDRVVDAASRVG

(122) IKIIINFVNYWTDYGGMSAYVSAYGGSDETDFYTSDTMQSAYRTYIKTVVERYSNSSAVVAWELA

(187) NEPRC -------PSCDTSVLYDWIERTSRFIKGLDADHMVCI GDEGFGLNTDSDGSYPYQE NEPRCGADGVRNL PRSDNCNPQVLGEWVAEMSQYIKSLDPNHLVTWGGEG-GFNRESD-DWAYNG

296

(241) AEGLNETRNIGIDTIDEGTLHLYPDWGTSDDWGNGWISAHGAACR, AGRPCLLEEYGTSNHCS SDGGDFDHEISLDTIDFGVFHSYPDWWSRMVEWTDQWIRDHAEAGR AGKPVVHEEYG VIPEAR

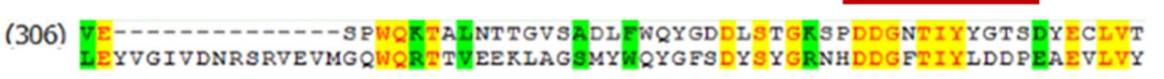

(357) DHVAAIGSA------

QHAEEMQSLNSEARS

B

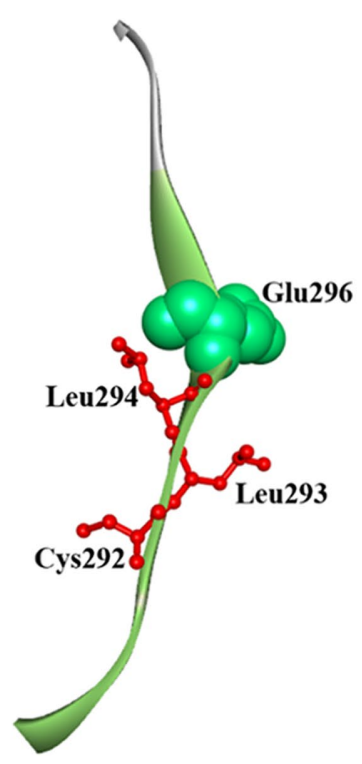

C

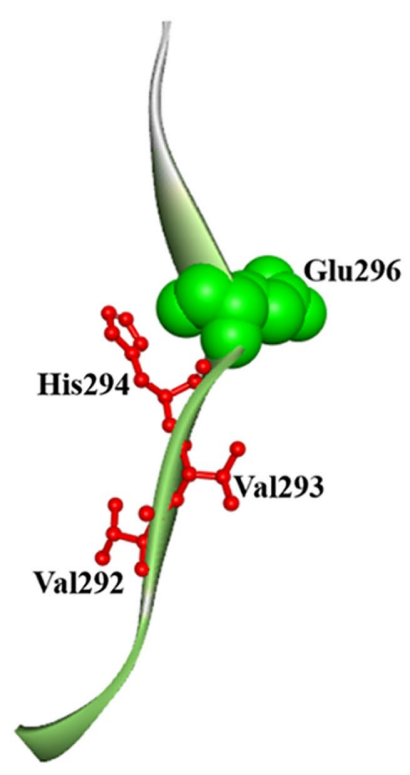

FIGURE 1 | Amino acid consensus sequence analysis and secondary structure around E296 of thermostable and acidophilic $\beta$-mannanase (ManAK) and ManCbs. (A) Amino acid consensus sequence analysis of ManAK and ManCbs. Strictly conserved residues are shaded yellow. The active site residues in catalytic regions are boxed and circles indicate the catalytic sites in catalytic region. (B) Secondary structure around E296 of ManAK. (C) Secondary structure around E296 of ManCbs. The amino acids in position 292, 293, and 294 are indicated in red, and E296 is indicated in green balls.

supernatants were collected and analyzed according to the procedure as previously described (Katrolia et al., 2013), using TLC plate (Silica gel 60F254, Merck, Darmstadt, Germany) to analyze the samples.

The hydrolysis products of recombinant ManAK and the mutant ManAK ${ }^{\mathrm{L} 293 \mathrm{~V}}$ were further analyzed using highperformance liquid chromatography [HPLC; Agilent 1260 Infinity system TSKgel G-oligo-PW column (7.5 mm $\times 300 \mathrm{~mm})$, Tosoh Corporation Co. Japan]. Purified ManAK and ManAK ${ }^{\mathrm{L} 293 \mathrm{~V}}$ were diluted with $50 \mathrm{mM}$ sodium acetate buffer ( $\mathrm{pH} 5.5)$ to give a final enzyme activity of $5 \mathrm{U}$, and reacted with $20 \mathrm{mM}$ MOS standard solution (M4 and $\mathrm{M} 5$ ) at $37^{\circ} \mathrm{C}$ for $20 \mathrm{~min}$. The products were detected with ultra-pure water as the mobile phase at a flow rate of $0.6 \mathrm{ml} / \mathrm{min}$. All samples were injected after filtering through a $0.22 \mu \mathrm{m}$ filter membrane, and the hydrolysis products were analyzed sequentially.

The release of reducing sugar was determined as follows: $5 \mathrm{U}$ purified enzyme and $0.5 \%(\mathrm{w} / \mathrm{v}) \mathrm{D}$-mannan (Sigma, United States) in $50 \mathrm{mM}$ sodium acetate buffer ( $\mathrm{pH} 5.5)$ were incubated at $37^{\circ} \mathrm{C}$ for varying lengths of time, and the concentration of released reducing sugars measured by the DNS method as above.

To explore the application of this $\beta$-mannanase, the recombinant ManAK and the ManAK ${ }^{\mathrm{L} 293 \mathrm{~V}}$ mutant were assessed for their hydrolytic performance, using LBG as a substrate. 
LBG was dissolved in $50 \mathrm{mM}$ sodium acetate buffer ( $\mathrm{pH} 5.5$ ) to give a final concentration of $1.0 \%$, and purified ManAK and $\mathrm{ManAK}^{\mathrm{L} 293 \mathrm{~V}}$ were diluted with $50 \mathrm{mM}$ sodium acetate buffer ( $\mathrm{pH} 5.5)$ to 5 enzyme activity units. The reaction was carried out at $37^{\circ} \mathrm{C}$ for $12 \mathrm{~h}$. Molecular weight distribution of the hydrolysis products was detected by the HPLC [Agilent 1260 Infinity system TSKgel G4000PWXL column $(7.8 \mathrm{~mm} \times 300 \mathrm{~mm})$, Tosoh Corporation Co. Japan]. The mobile phase of the detection system was $0.2 \mathrm{M} \mathrm{NaNO}$ and $0.01 \mathrm{M} \mathrm{NaH} \mathrm{PO}_{4}$, and the flow rate was $0.2 \mathrm{ml} / \mathrm{min}$.

TABLE 2 | Kinetic parameters of ManAK, ManAK ${ }^{\mathrm{C} 292 \mathrm{~V}}$, ManAK ${ }^{\mathrm{L} 293 \mathrm{~V}}$, and ManAK ${ }^{\text {L294H }}$.

\begin{tabular}{|c|c|c|c|c|}
\hline & $\begin{array}{l}V_{\max }(U / \\
\mathrm{mg} \cdot \min )\end{array}$ & $\mathrm{K}_{\mathrm{m}}(\mathrm{mg} / \mathrm{ml})$ & $\mathbf{K}_{\text {cat }}\left(\mathbf{S}^{-1}\right)$ & $\begin{array}{c}\mathrm{K}_{\mathrm{cat}} / \mathrm{K}_{\mathrm{m}}(\mathrm{ml} / \\
\mathbf{s} \cdot \mathrm{mg})\end{array}$ \\
\hline ManAKC292V & $126.80 \pm 8.29$ & $0.10 \pm 0.09$ & 83.67 & 803.22 \\
\hline ManAK & $154.22 \pm 12.32$ & $0.14 \pm 0.12$ & 101.72 & 758.07 \\
\hline ManAK & $64.29 \pm 20.52$ & $0.07 \pm 0.18$ & 42.41 & 618.01 \\
\hline ManAK & $329.30 \pm 25.50$ & $1.09 \pm 0.28$ & 217.21 & 199.30 \\
\hline
\end{tabular}

\section{Statistical Analysis}

All experimental results were repeated three times, and they were statistically analyzed using ANOVA ( $t$-test) with IBM SPSS Statistics 26 software. Differences with a threshold of $p<0.05$ were considered statistically significantly.

\section{RESULTS}

\section{Sequence Alignment Analysis of ManAK and ManCbs Based on CSD Strategy}

Analysis of the conserved domains of the gene sequences of ManAK and ManCbs showed that they both belonged to the GH5 family, and that the proportion of amino acid sequence homology in the catalytic region was as high as 86.4\%. Two key amino acids (Glu188 and Glu296) in the catalytic sites of ManAK exist as proton donors and nucleophiles, respectively, which play an important role in hydrolysis (Zhang et al., 2019). When ManAK binds to the substrates, a catalytic cleft is formed between the two catalytic
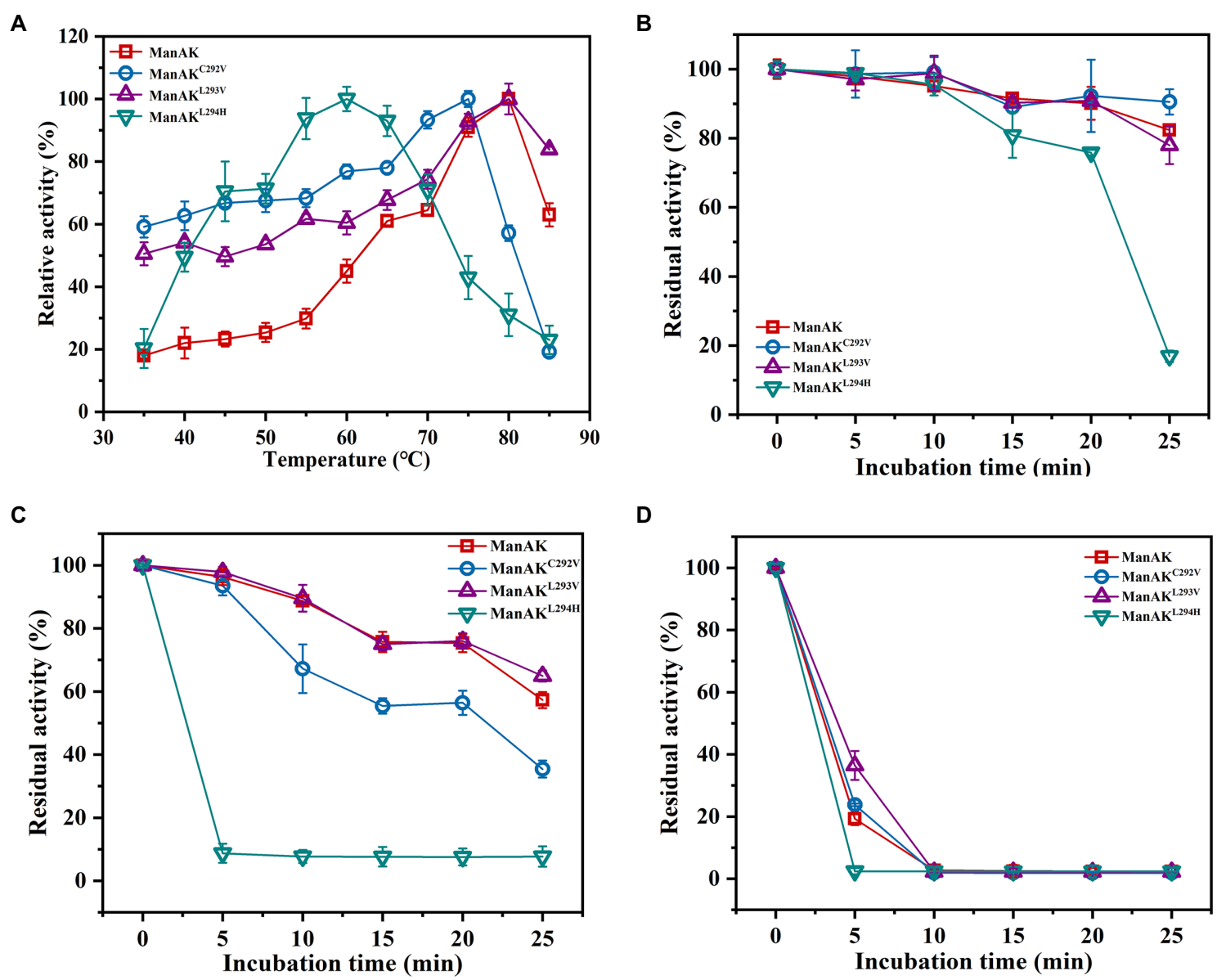

FIGURE 2 | Effects of temperature on activity and stability of recombinant $\beta$-mannanases. (A) The optimum temperature was determined in 50 mM sodium acetate buffer ( $\mathrm{pH} 5.5$ ) with a range of $35-85^{\circ} \mathrm{C}$ for $5 \mathrm{~min}$; the thermal stability was evaluated under standard conditions ( $\mathrm{pH} 5.5,37^{\circ} \mathrm{C}$, and $30 \mathrm{~min}$ ) after the enzymes without substrate were treated at 60 (B), 70 (C), and $80^{\circ} \mathrm{C}$ (D) for $5-25 \mathrm{~min}$. 
domains (Glu188 and Glu296), and the amino acid residues around them assist with hydrolysis (Hilge et al., 1998).

The sequence comparison also showed that the amino acid sequence of the catalytic region around Glu188 was highly consistent (Figure 1). However, the amino acids around Glu296 in ManAK (Cys292, Cys293, and Leu294) were different from those in ManCbs (Val292, Val293, and His294). Combined with the structural analysis of ManAK and ManCbs in the catalytic region of Glu296, it was shown that the three different amino acids in positions 292, 293, and 294 were in the same $\beta$-sheet structure, and were adjacent to Glu298 (Figures 1B,C). The amino acid sequence of the three sites is likely to have a significant impact on the catalytic efficiency of the enzyme. Thus, through consensus sequence analysis, and structure analysis on the different amino acids in catalytic region, three mutants (ManAK $^{\mathrm{C} 292 \mathrm{~V}}$, ManAK ${ }^{\mathrm{L} 293 \mathrm{~V}}$, and ManAK ${ }^{\mathrm{L} 294 \mathrm{H}}$ ) were constructed to assess the underlying influences of the three amino acids on the catalytic efficiency of ManAK.

\section{Kinetic Parameters and Catalytic Efficiency of Recombinant Mannanases}

The recombinant plasmids $\mathrm{pPICZ} \alpha$ A-ManAK ${ }^{\mathrm{C} 292 \mathrm{~V}}, \mathrm{pPICZ} \alpha$ $\mathrm{A}-\mathrm{ManAK}^{\mathrm{L} 293 \mathrm{~V}}$, pPICZ $\alpha$ A-ManAK ${ }^{\mathrm{L} 294 \mathrm{H}}$ were transformed into the expression host $P$. pastoris X33. SDS-PAGE showed that the detected molecular weights of recombinant enzymes were approximately $50 \mathrm{kDa}$.

Locust bean gum was used as a substrate to determine the kinetic parameters of ManAK and its mutants. According to the Michaelis-Menten equation, the results demonstrated that the $V_{\max }$ and $\mathrm{K}_{\mathrm{m}}$ values of ManAK were $329.3 \mathrm{U} / \mathrm{mg} \cdot \mathrm{min}$ and $1.09 \mathrm{mg} / \mathrm{ml}$, and the catalytic efficiency $\mathrm{k}_{\text {cat }} / \mathrm{K}_{\mathrm{m}}$ value was $199.3 \mathrm{ml} / \mathrm{s} \cdot \mathrm{mg}$ (Table 2). Although, the $\mathrm{V}_{\max }$ of the three recombinant mannanases was not obviously improved, the $\mathrm{K}_{\mathrm{m}}$ values were changed from $1.09 \mathrm{mg} / \mathrm{ml}$ (ManAK) to $0.10 \mathrm{mg} /$ $\mathrm{ml}\left(\mathrm{ManAK}^{\mathrm{C} 292 \mathrm{~V}}\right), 0.14 \mathrm{mg} / \mathrm{ml}\left(\mathrm{ManAK}^{\mathrm{L} 293 \mathrm{~V}}\right)$, and $0.07 \mathrm{mg} / \mathrm{ml}$ (ManAK ${ }^{\mathrm{L} 294 \mathrm{H}}$ ), which indicated that the substrate affinity of the three mutants was improved.

The mutated amino acids, Val292, Val293, and His294, were shown to greatly affect the catalytic efficiency of ManAK. The results revealed that the $\mathrm{k}_{\mathrm{cat}} / \mathrm{K}_{\mathrm{m}}$ values of the three recombinant mannanases ManAK ${ }^{\mathrm{C} 292 \mathrm{~V}}$, ManAK ${ }^{\mathrm{L} 293 \mathrm{~V}}$, and $\mathrm{ManAK}^{\mathrm{L} 294 \mathrm{H}}$ were enhanced by 303.0, 280.4, and 210.1\%, respectively (Table 2). This proved that the CSD strategy was effective in improving the catalytic efficiency of mannanase. Further study is needed to show whether other properties of the enzyme could be similarly improved using this modification strategy.

\section{Other Biochemical Characteristics of ManAK and Mutants}

Thermostable and acidophilic $\beta$-mannanase showed excellent temperature characteristics with an optimal temperature for activity of $80^{\circ} \mathrm{C}$ (Figure $2 \mathrm{~A}$ ); and even retained approximately $19.3 \%$ of enzyme activity after incubation at $80^{\circ} \mathrm{C}$ for $5 \mathrm{~min}$ (Figure 2D). Three mutants of ManAK were constructed and their biochemical characteristics were accessed. While the catalytic efficiency was improved, the thermal stability of
$\operatorname{ManAK}^{\mathrm{L} 293 \mathrm{~V}}$ was further enhanced. Compared with the original enzyme ManAK, the optimum temperature of ManAK ${ }^{\mathrm{L} 293 \mathrm{~V}}$ was unchanged, remaining at $80^{\circ} \mathrm{C}$, but that of $\mathrm{ManAK}^{\mathrm{C} 292 \mathrm{~V}}$ and ManAK ${ }^{\mathrm{L} 294 \mathrm{H}}$ dropped to 75 and $60^{\circ} \mathrm{C}$, respectively (Figure 2A). Interestingly, after heating at $80^{\circ} \mathrm{C}$ for $5 \mathrm{~min}$, ManAK ${ }^{\mathrm{L} 293 \mathrm{~V}}$ retained $36.5 \%$ of the initial enzymatic activity, while ManAK retained only $19.3 \%$ (Figure 2D).

The ManAK is an extremely acidophilic mannanase with an optimal $\mathrm{pH}$ of 2.0 (Figure $3 \mathbf{A}$ ), and after treatment in a buffer solution at $\mathrm{pH} 2.0,84.3 \%$ relative enzymatic activity of ManAK was retained. Similarly, the $\mathrm{pH}$ profiles of the three mutants revealed that they retained strong activity under acidic conditions, and the optimal $\mathrm{pH}$ was acidic (Figure 3A). However, ManAK ${ }^{\mathrm{L} 294 \mathrm{H}}$ only retained $3.68 \%$ activity after

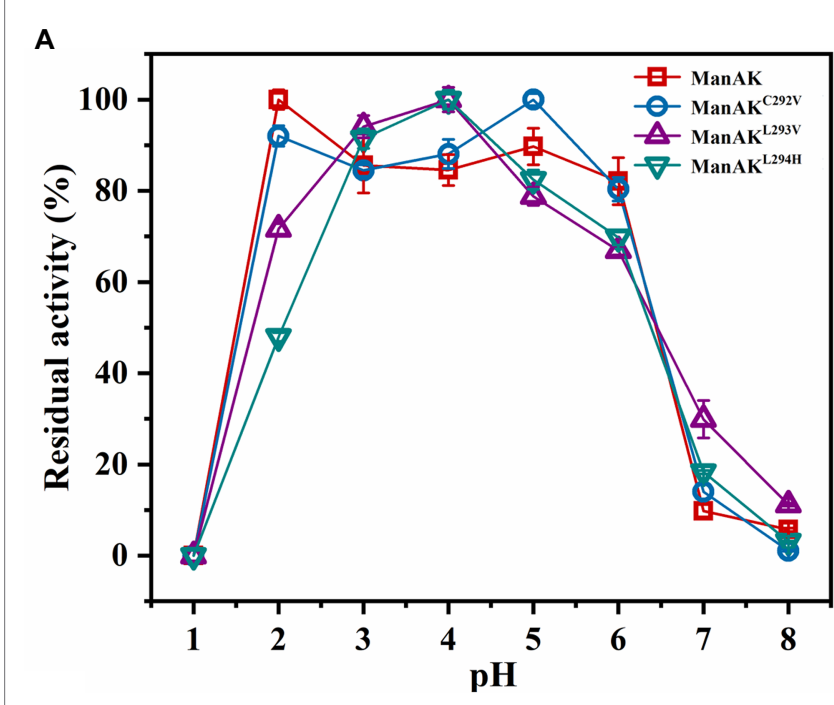

B

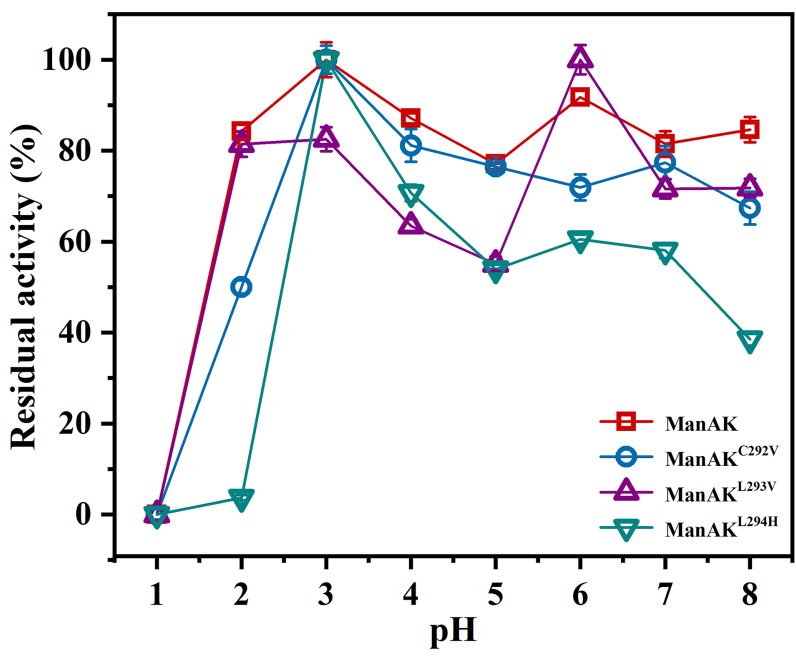

FIGURE 3 | Effects of $\mathrm{pH}$ on activity and stability of recombinant $\beta$-mannanases. (A) The $\mathrm{pH}$ optimum was determined in glycine- $\mathrm{HCl}$ buffer $(\mathrm{pH}$ 1.0-4.0), sodium acetate buffer ( $\mathrm{pH} 4.0-6.0)$, and Tris-HCl buffer $(\mathrm{pH}$ 6.0-8.0), respectively. (B) The $\mathrm{pH}$ stability was determined after the enzymes were incubated at $37^{\circ} \mathrm{C}$ for $2 \mathrm{~h}$ in different buffers as described above. 
A

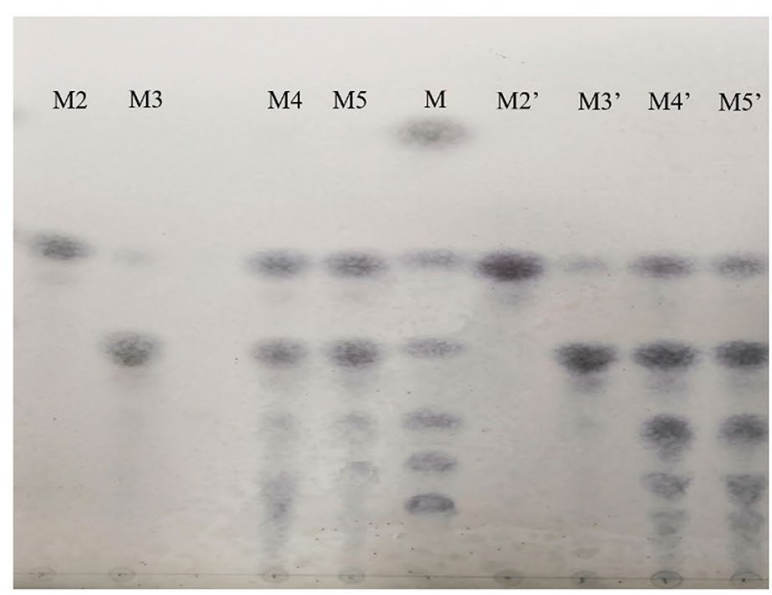

C

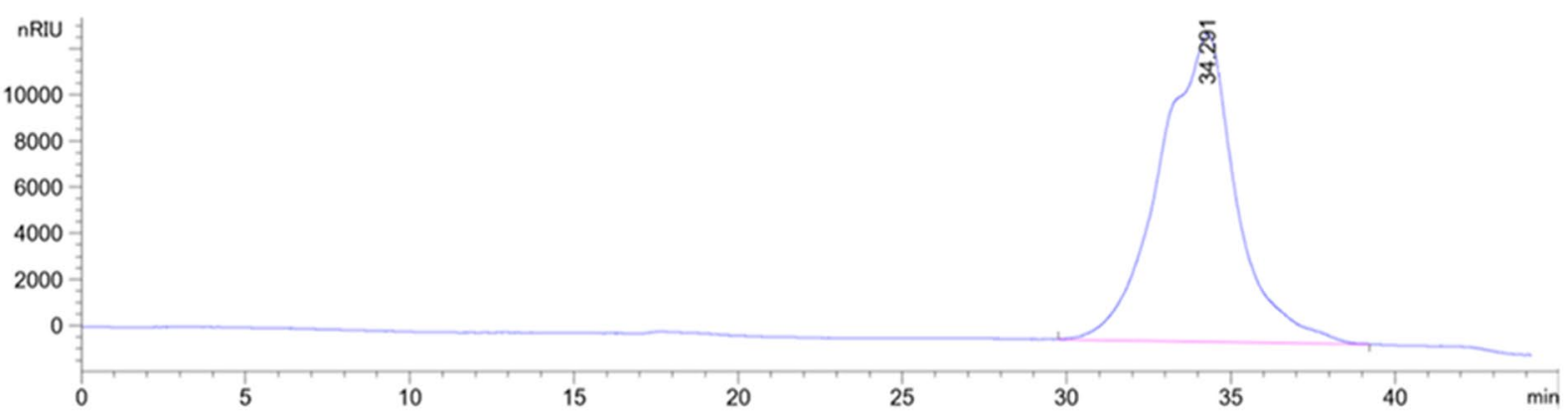

D

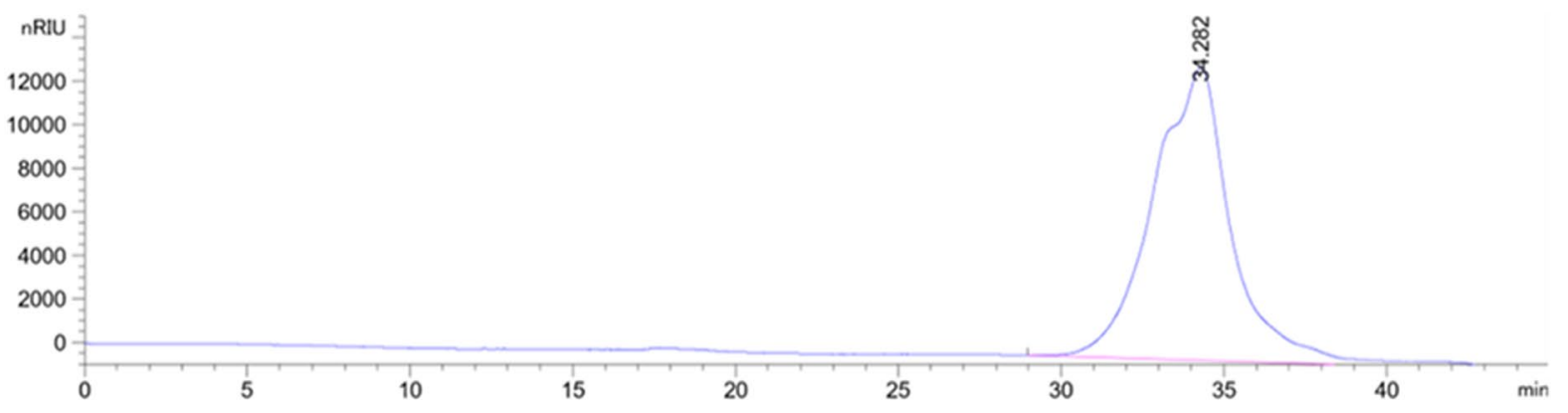

FIGURE 4 | Analysis of hydrolysis products. (A) The hydrolysis of substrates by ManAK and ManAK ${ }^{\text {L293V }}$, and thin-layer chromatography (TLC) analysis of hydrolysis products from manno-oligosaccharides (MOS) standards (M2-M5). The reaction was carried out at $37^{\circ} \mathrm{C}$ for $10 \mathrm{~min}$, and the reactants were $5 \mathrm{U}$ purified enzyme and $20 \mathrm{mM}$ MOS standard solution. Lanes: (M) the MOS standards consist of mannose, mannobiose, manninotriose, mannotetrose, mannopentose, and mannohexose (from top to bottom; M2-M5) the hydrolysis products of mannobiose, manninotriose, mannotetrose, and mannopentose, respectively, (M2'-M5') the same indication as above, analysis of hydrolysis products of ManAK ${ }^{2932}$. (B) The release of reducing sugar concentration of recombinant mannanases incubated with D-mannan in $50 \mathrm{mM}$ sodium acetate buffer ( $\mathrm{pH} 5.5)$ at $37^{\circ} \mathrm{C}$. (C) High-performance liquid chromatography (HPLC) analysis of the molecular weight distribution of hydrolysis products from locust bean gum (LBG) by ManAK (reaction carried out at $37^{\circ} \mathrm{C}$ for $12 \mathrm{~h}$ ). (D) HPLC analysis of the molecular weight distribution of hydrolysis products from LBG by ManAK ${ }^{\mathrm{L} 293 \mathrm{~V}}$ (reaction carried out at $37^{\circ} \mathrm{C}$ for $12 \mathrm{~h}$ ).
B

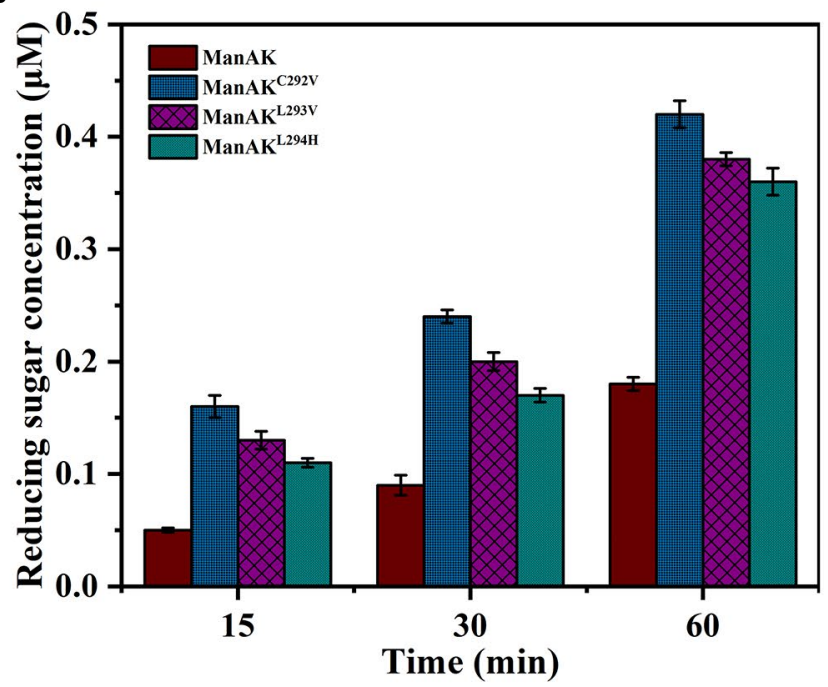


TABLE 3 | High-performance liquid chromatography analysis of the hydrolysis products of mannan polymers by ManAK and ManAK ${ }^{L 293 \mathrm{~V}}$.

\begin{tabular}{|c|c|c|c|c|c|c|}
\hline \multirow{2}{*}{ Substrate } & \multicolumn{6}{|c|}{ Composition $(\%)$ of products formed by hydrolysis reaction } \\
\hline & M1 & M2 & M3 & M4 & M5 & M6 \\
\hline \multicolumn{7}{|l|}{ ManAK } \\
\hline M4 & 6.3 & 20.9 & 42.9 & 23.6 & 4.9 & 1.2 \\
\hline M5 & 16.4 & 21.1 & 36.4 & 17.5 & 8.1 & 0.4 \\
\hline \multicolumn{7}{|l|}{ ManAK ${ }^{\mathrm{L} 293 \mathrm{~V}}$} \\
\hline M4 & 7.2 & 22.4 & 43.5 & 20.1 & 6.2 & 0.6 \\
\hline M5 & 15.4 & 25.6 & 38.2 & 13.1 & 6.9 & 0.8 \\
\hline
\end{tabular}

treatment in a buffer solution at $\mathrm{pH} 2.0$, possibly because $\mathrm{H} 294$ is a basic amino acid (Figure 3B).

\section{Analysis of Hydrolysis Products}

In order to verify whether the hydrolytic performance of the recombinant mannanase was affected, the hydrolysis products from the mutant ManAK ${ }^{\mathrm{L} 293 \mathrm{~V}}$ and ManAK were compared. The results showed that there was no significant difference between the hydrolysis products (Figures 4A,C,D), indicating that the site-mutation of $\mathrm{L} 293 \mathrm{~V}$ had no negative influence on hydrolysis.

The enzymes were unable to cleave M2 and showed very limited cleavage of M3, which indicated that ManAK was an endo-mannanase (Figure $\mathbf{4 A}$ ). The enzymes were able to efficiently hydrolyze M4 and M5, proving that the enzyme was useful for the preparation of prebiotic oligosaccharides. In addition, M5 sugars were detected during the hydrolysis of M4 (Figure 4A), showing that ManAK and ManAK ${ }^{\mathrm{L} 293 \mathrm{~V}}$ shared similar transglycosylation activity. Therefore, the modification strategy used in this work did not affect the hydrolysis mode.

According to the results of the TLC analysis, M4 and M5 were selected as substrates to further analyze the hydrolysis products by the HPLC. The results were consistent with the results of TLC analysis. As show in Table 3, both ManAK and $\mathrm{ManAK}^{\mathrm{L} 293 \mathrm{~V}}$ can effectively degrade M4 and M5 to generate small molecule oligosaccharides, and M5 can be detected during the degradation of M4, and M6 can be detected during the degradation of M5. Furthermore, when degrading M4 and M5, the main products generated by ManAK were M3, with a composition of 42.9 and $36.4 \%$, respectively.

To better understand the improvement in catalytic efficiency of the three recombinant mannanases, the reducing sugars released were measured under the same conditions. The results demonstrated that the yields of reducing sugars of the different mutants were all higher than that of ManAK, which corresponded with the results of the kinetic analysis (Figure 4B).

Locust bean gum was used as a substrate to illustrate the application potential of ManAK and the mutant ManAK ${ }^{\mathrm{L} 293 \mathrm{~V}}$. The results showed that they can effectively degrade LBG (Figures 4C,D), and the products hydrolyzed were oligosaccharides with a molecular weight below 3,000 Da, which indicated that ManAK had application potential in the preparation of MOS.

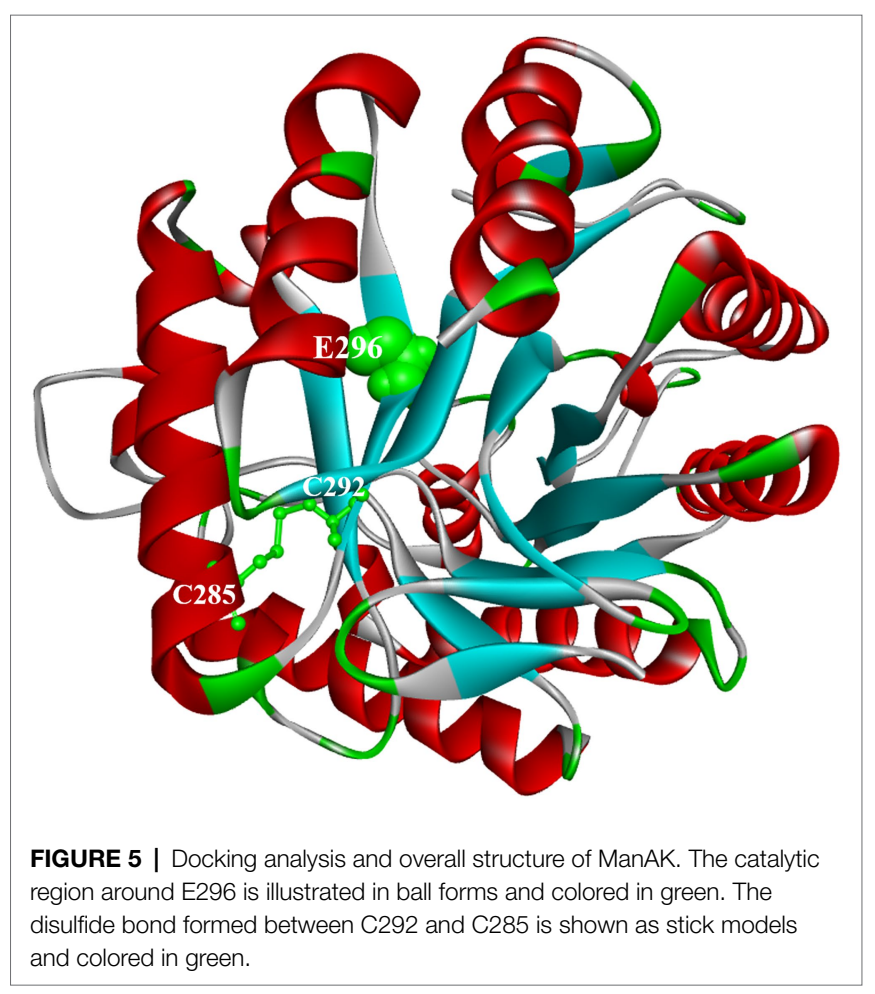

\section{Analysis of Structures and Interaction Forces in Mutated Sites of ManAK and Mutants}

The three-dimensional structures of ManAK and recombinant mutants were modeled. The results showed that the structures and interaction forces of the three mutants at the mutated sites were changed compared with those of ManAK (Figures 5-7). The modeled three-dimensional structure of ManAK indicated that a disulfide bond was formed between C292 and C285 (Figure 5). The ManAK ${ }^{\mathrm{C} 292 \mathrm{~V}}$ mutation destroyed the disulfide bond seen in the original enzyme. As shown in Figure 6, ManAK and ManAK ${ }^{\mathrm{L} 293 \mathrm{~V}}$ both had a parallel folded $\beta$-sheet, while ManAK ${ }^{\mathrm{L} 293 \mathrm{~V}}$ had a newly force (Alkyl) compared with the original interaction forces (van der Waals, Pi-Alkyl, Conventional Hydrogen Bond, and Covalent bond) seen in ManAK. The modeled structures of ManAK ${ }^{\mathrm{L} 294 \mathrm{H}}$ and ManAK in position 294 showed that they all involved in the secondary structure of $\alpha$-helix and $\beta$-sheet (Figures $7 \mathbf{A}, \mathbf{B}$ ). 
However, the results of analysis of interaction forces at the 294 position demonstrated that the mutant $\mathrm{ManAK}^{\mathrm{L} 294 \mathrm{H}}$ had a newly introduced $\mathrm{Pi}$-Pi stacked interaction and one less conventional hydrogen bond than ManAK (Figures 7C,D).

\section{DISCUSSION}

Since $\beta$-mannanase has excellent potential in the production of industrial feedstuff, its catalytic efficiency has garnered attention. In this study, CSD strategy, a method previously used to improve the catalytic efficiency of $\beta$-glucosidases (Ratananikom et al., 2013), was applied to ManAK. The $\mathrm{K}_{\mathrm{m}}$ values of the three mutants were reduced compared with
ManAK, which demonstrated that mutations (C292V, L293V, and L294H) could improve the substrate affinity of ManAK. The $\mathrm{K}_{\mathrm{m}}$ values of the mutants were also lower than those of most reported mannanases, such as those from Bacillus sp. HJ14 $(2.20 \mathrm{mg} / \mathrm{ml}$; Zhang et al., 2016), Phialophora sp. P13 (2.50 mg/ml; Zhao et al., 2010), Bacillus sp. JAMB-602 (3.10 mg/ml; Takeda et al., 2004), Bacillus halodurans PPKS-2 (3.85 mg/ml; Vijayalaxmi et al., 2013), Phialophora pinophilum C1 $(5.60 \mathrm{mg} / \mathrm{ml}$; Cai et al., 2011), Bacillus subtilis BE-91 (7.14 mg/ ml; Cheng et al., 2016), Bacillus nealsonii PN-11 $(7.22 \mathrm{mg} / \mathrm{ml}$; Chauhan et al., 2014b), B. subtilis WY34 $(7.60 \mathrm{mg} / \mathrm{ml}$; Jiang et al., 2006), B. subtilis MAFIC-S11 $(8.00 \mathrm{mg} / \mathrm{ml}$; Lv et al., 2013), Bacillus sp. MSJ-5 (11.67 mg/ml; Zhang et al., 2009), and B. subtilis YH12 (30.00 mg/ml; Liu et al., 2015).
A

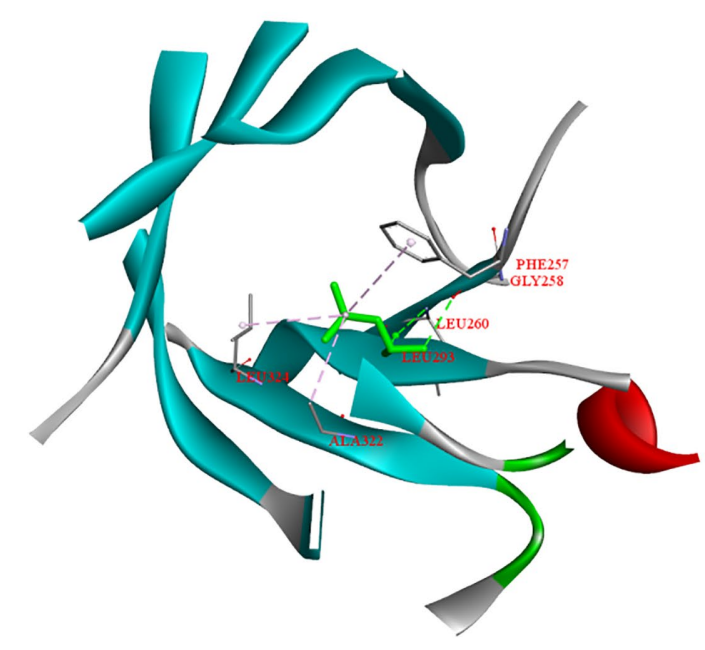

B

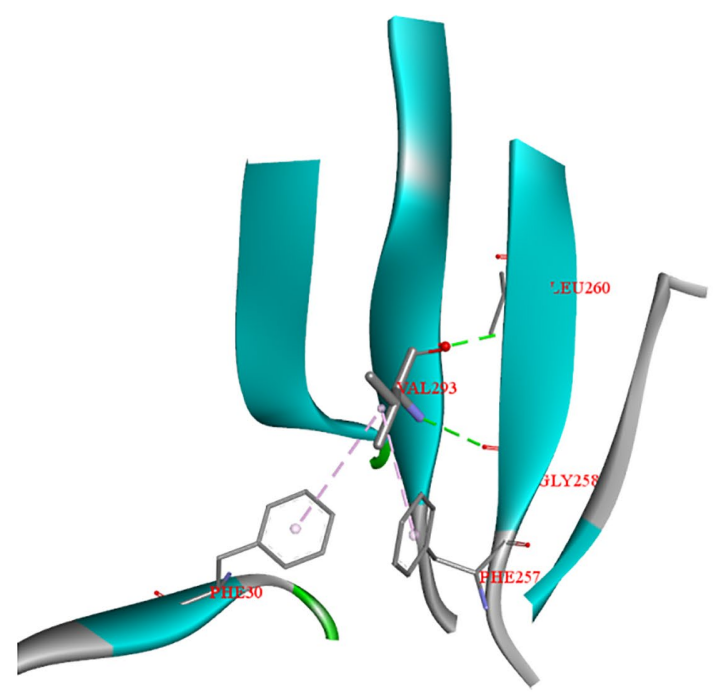

C

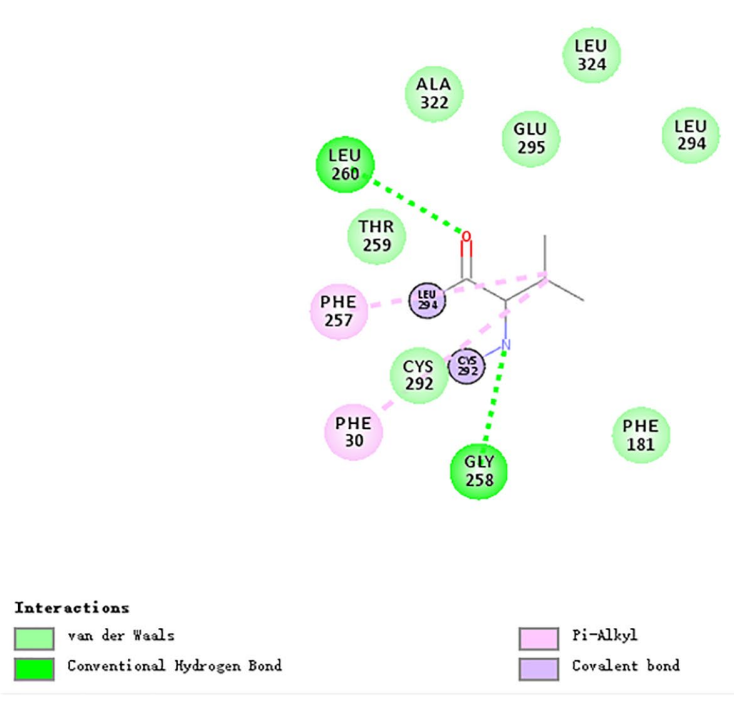

D

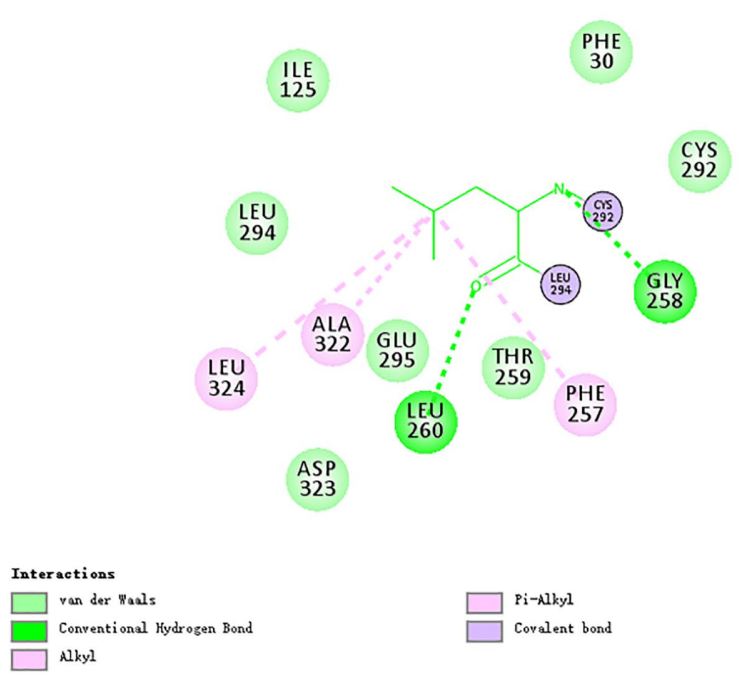

FIGURE 6 | Overall structure and modeled complex structures of ManAK (A) and ManAK ${ }^{293 v}$ (B) in position 293. The amino acid residues around position 293 are indicated in red. The interactions between them are represented by a dashed line. Interaction analysis of amino acid site ManAK (C) and ManAK ${ }^{\llcorner 293 \mathrm{~V}}$ (D). The green dashed line indicates Conventional Hydrogen Bond interaction; the pink dashed line indicates Alkyl and Pi-Alkyl interaction. Amino acid residues that form van der Waals interactions with amino acid in position 293 are indicated in light green balls and Covalent bond are indicated in purple. 


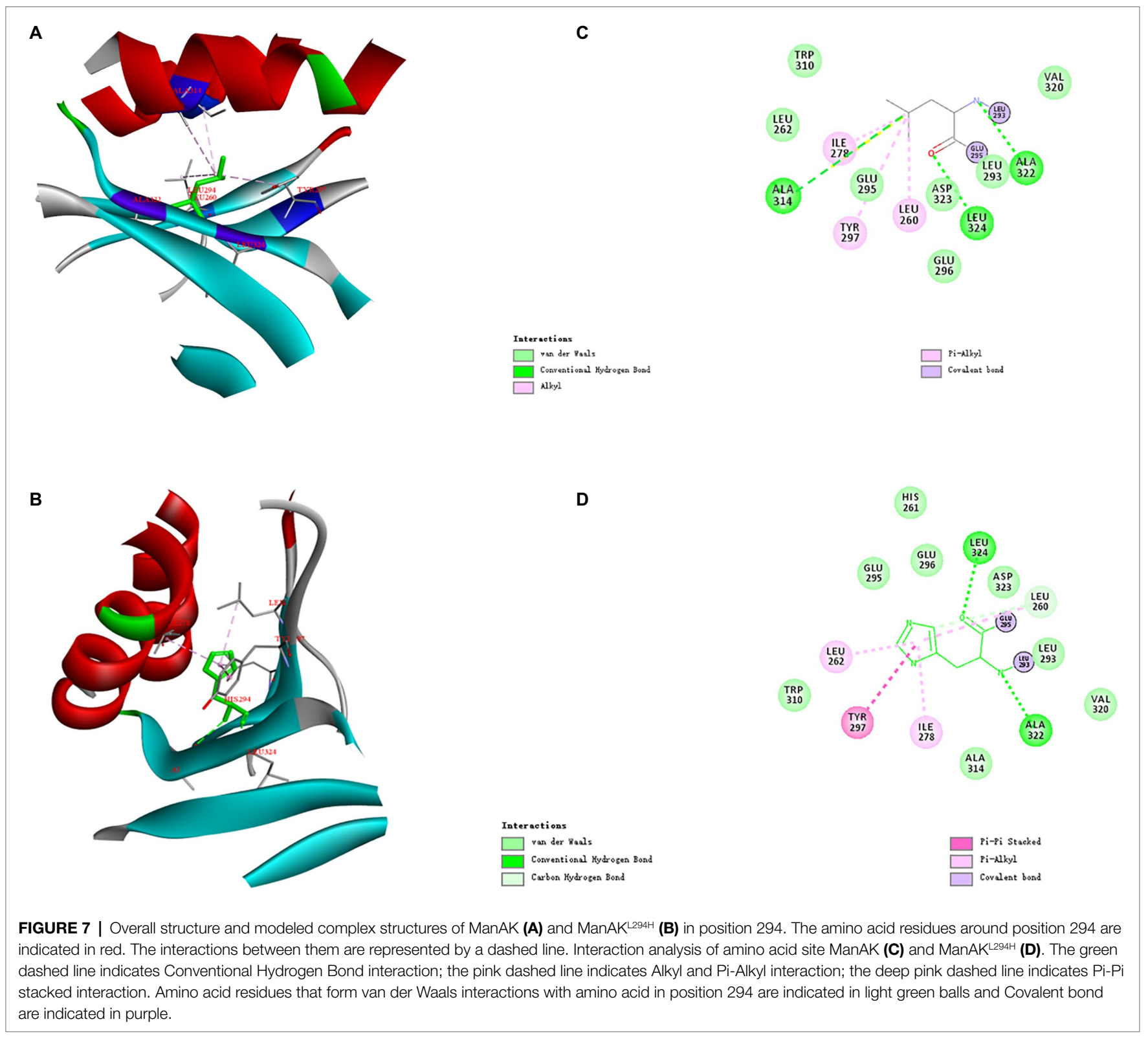

The $\mathrm{k}_{\text {cat }} / \mathrm{K}_{\mathrm{m}}$ of the three mutants was significantly improved compared to ManAK. This was superior to the previously reported catalytic efficiency of mannanases, such as those from Penicillium canescens (Sinitsyna et al., 2008) and Rhizomucor miehei (Katrolia et al., 2012). The substrate affinity of the three mutants was greatly enhanced due to the significant decrease in $K_{m}$ values, which might increase the $k_{c a t} / K_{m}$ values. However, the improvement in catalytic efficiency may be limited. With the constant increase in substrate concentration, the advantage of high catalytic efficiency may be reduced. In fact, within a certain range of substrate concentrations, these three recombinant mannanases can show superior catalytic efficiency. Moreover, interestingly, even though these three mutants all displayed elevated catalytic efficiencies, changes in their thermostability were either improved $\left(\mathrm{ManAK}^{\mathrm{L} 293 \mathrm{~V}}\right)$, remained the same $\left(\operatorname{ManAK}^{\mathrm{C} 292 \mathrm{~V}}\right)$, or decreased $\left(\operatorname{ManAK}^{\mathrm{L} 294 \mathrm{H}}\right)$.
Nowadays, molecular simulation is widely used to infer the changes of non-covalent forces in the mutation site region before and after the alteration, which is helpful to explain the reasons for the changes in the thermostability and the catalytic efficiency of mutants. Molecular simulation can be used for most enzymes, including mannanases (Chauhan et al., 2015; Chauhan and Jaiswar, 2017; Liu et al., 2020a), xylanase (Cheng et al., 2015), and $\beta$-glucosidases (Dadheech et al., 2019). Therefore, in this study, the structure-function relationships of the three mutants were analyzed by docking analysis and a molecular simulation method.

ManAK ${ }^{\mathrm{C} 222 \mathrm{~V}}$ showed elevated catalytic efficiency, which was increased by $303.0 \%$ compared with the starting enzyme ManAK, and a reduced $\mathrm{K}_{\mathrm{m}}$ value. The modeled three-dimensional structure of ManAK indicated that a disulfide bond was formed between C292 and C285 (Figure 5). After the mutation, amino acid V292 destroyed the original disulfide bond, which in turn affected 
the original spatial structure. ManAK ${ }^{\mathrm{C} 292 \mathrm{~V}}$ eliminated the disulfide bond to provide more flexibility at the active site, and the flexibility of the $\beta$-sheet in the catalytic region E296 was also increased, possibly increasing the affinity between enzyme and substrate. However, the thermal stability of $\mathrm{ManAK}^{\mathrm{C} 292 \mathrm{~V}}$ was reduced (Figures $\mathbf{2 A}, \mathbf{C}$ ), possibly because the disulfide bond contributes to the maintenance of the stability of the enzyme.

The mutant ManAK ${ }^{\mathrm{L} 293 \mathrm{~V}}$ showed increased catalytic activity, suggesting the importance of residue V293. The alkyl side chain of V293 was smaller than that of L293, which meant that the steric hindrance of this amino site was smaller, indicating that it provided a larger space for substrate entry and product release. Interestingly, mutant $\mathrm{ManAK}^{\mathrm{L} 293 \mathrm{~V}}$ also showed improved thermal stability. No significant difference was detected in the spatial structure at this position between ManAK and ManAK ${ }^{\mathrm{L} 293 \mathrm{~V}}$, with both having a parallel folded $\beta$-sheet (Figures 6A,B). However, a newly formed interaction force between alkyl groups (Figures 6C,D) might have a positive influence on the thermal stability of enzyme, which meant that V293 was thought to be the critical site for the improvement of stability.

Similar results for ManAK ${ }^{\mathrm{L} 294 \mathrm{H}}$ were observed in both the kinetic study and catalytic ability; it displayed a lower $\mathrm{K}_{\mathrm{m}}$ value and higher catalytic efficiency, which meant the substrate-binding affinity was greatly increased. Residue Y297 of ManAK is located adjacent to the key catalytic amino site E296, and although, it might not directly interact with the substrate it generated a $\pi-\pi$ stacking interaction with the new corresponding residue of H294 (Figure 7D). The substitution of H294 has a heteroaryl structure, which tends to form the $\pi-\pi$ stacking interaction with the substrates, thus promoting the substrate-binding affinity and catalytic efficiency. Similar cases have been reported in previous studies in which a new stacking force is formed by the aryl of the mutant amino acid, and is conducive to substrate entry (Huang et al., 2014; Cheng et al., 2015). In contrast to the positive results, ManAK ${ }^{\mathrm{L} 294 \mathrm{H}}$ showed a drastically reduced optimum temperature and thermal stability (Figures 2A-D). From the complex structure model in 294 position, ManAK had a conventional hydrogen bond between L294 and A314 (Figure 7C), and involved in $\alpha$-helix and $\beta$-sheet (Figure 7A). In ManAK ${ }^{\mathrm{L} 294 \mathrm{H}}$, the conventional hydrogen bond was destroyed and the secondary structure of $\alpha$-helix was excluded (Figure 7B), indicating that the conventional hydrogen bond between L294 and A314 is indispensable for the stability of ManAK. The destruction and disappearance of this original force may have a negative impact on the stability of the protein itself.

\section{REFERENCES}

Bradford, M. M. (1976). A rapid and sensitive method for the quantitation of microgram quantities of protein utilizing the principle of protein-dye binding. Anal. Biochem. 72, 248-254. doi: 10.1016/0003-2697(76)90 527-3

Cai, H., Shi, P., Luo, H., Bai, Y., Huang, H., Yang, P., et al. (2011). Acidic $\beta$-mannanase from Penicillium pinophilum $\mathrm{C} 1$ : cloning, characterization and assessment of its potential for animal feed application. J. Biosci. Bioeng. 112, 551-557. doi: 10.1016/j.jbiosc.2011.08.018

Chauhan, P. S., and Jaiswar, S. (2017). Molecular dynamic simulation studies of bacterial thermostable mannanase unwinding the enzymatic catalysis. Biocatal. Agric. Biotechnol. 9, 41-47. doi: 10.1016/j.bcab.2016.11.003

\section{CONCLUSION}

A thermostable and acidophilic $\beta$-mannanase, ManAK, derived from marine Aspergillus kawachii IFO 4308 would be especially suitable for MOS preparation, except for its low catalytic efficiency. To compensate for this defect, a CSD method was adopted to engineer the catalytic efficiency of ManAK. Three positive mutants (ManAK ${ }^{\mathrm{C} 292 \mathrm{~V}}$, ManAK ${ }^{\mathrm{L} 293 \mathrm{~V}}$, and ManAK ${ }^{\mathrm{L} 294 \mathrm{H}}$ ) showing increased $\mathrm{k}_{\mathrm{cat}} / \mathrm{K}_{\mathrm{m}}$ values were generated. Minor changes were detected in their optimal $\mathrm{pH}$ values and acid tolerance, while their thermostabilities varied. The mechanisms underlying the stability and catalytic efficiency were investigated, which provided an intuitive understanding of structure-function relationships. Most importantly, a superior mutant $\left(\mathrm{ManAK}^{\mathrm{L} 293 \mathrm{~V}}\right)$ with both enhanced catalytic efficiency and thermostability was acquired, which can further advance the application of ManAK in MOS preparation.

\section{DATA AVAILABILITY STATEMENT}

The original contributions presented in the study are included in the article/Supplementary Material, further inquiries can be directed to the corresponding authors.

\section{AUTHOR CONTRIBUTIONS}

QL contributed to the experiment planning and conduct, writing - original draft preparation, and methodology. YZ and MY also contributed to experiment conduct and revision of the writing - original draft. LC contributed to data collation and analysis, graphics drawing, and statistical analysis. CZ contributed to write and revise the manuscript. ZL contributed to software application, conceptualization, and data curation. HM contributed to writing-review, supervision, funding acquisition, and project administration. All authors contributed to the article and approved the submitted version.

\section{FUNDING}

This work was supported by National Key Research and Development (R\&D) Program of China 2019YFD0901805 and National Nature Science Fund of China 31872893.

Chauhan, P. S., Puri, N., Sharma, P., and Gupta, N. (2012). Mannanases: microbial sources, production, properties and potential biotechnological applications. Appl. Microbiol. Biotechnol. 93, 1817-1830. doi: 10.1007/s00253-012-3887-5

Chauhan, P. S., Sharma, P., Puri, N., and Gupta, N. (2014a). Purification and characterization of an alkali-thermostable $\beta$-mannanase from Bacillus nealsonii $\mathrm{PN}-11$ and its application in mannooligosaccharides preparation having prebiotic potential. Eur. Food Res. Technol. 238, 927-936. doi: 10.1007/s00217-014-2170-7

Chauhan, P. S., Sharma, P., Puri, N., and Gupta, N. (2014b). A process for reduction in viscosity of coffee extract by enzymatic hydrolysis of mannan. Bioprocess Biosyst. Eng. 37, 1459-1467. doi: 10.1007/s00449-013-1118-9

Chauhan, P. S., Tripathi, S. P., Sangamwar, A. T., Puri, N., Sharma, P., and Gupta, N. (2015). Cloning, molecular modeling, and docking analysis of alkali-thermostable $\beta$-mannanase from Bacillus nealsonii PN-11. Appl. Microbiol. Biotechnol. 99, 8917-8925. doi: 10.1007/s00253-015-6613-2 
Cheng, Y. S., Chen, C. C., Huang, J. W., Ko, T. P., Huang, Z., and Guo, R. T. (2015). Improving the catalytic performance of a GH11 xylanase by rational protein engineering. Appl. Microbiol. Biotechnol. 99, 9503-9510. doi: 10.1007/ s00253-015-6712-0

Cheng, L., Duan, S., Feng, X., Zheng, K., Yang, Q., and Liu, Z. (2016). Purification and characterization of a thermostable $\beta$-mannanase from Bacillus subtilis BE-91: potential application in inflammatory diseases. Biomed. Res. Int. 2016, 1-7. doi: $10.1155 / 2016 / 6380147$

Dadheech, T., Jakhesara, S., Chauhan, P. S., Pandit, R., Hinsu, A., Kunjadiya, A., et al. (2019). Draft genome analysis of lignocellulolytic enzymes producing Aspergillus terreus with structural insight of $\beta$-glucosidases through molecular docking approach. Int. J. Biol. Macromol. 125, 181-190. doi: 10.1016/j. ijbiomac.2018.12.020

Finn, R. D., Bateman, A., Clements, J., Coggill, P., Eberhardt, R. Y., Eddy, S. R., et al. (2014). Pfam: The protein families database. Nucleic Acids Res. 42, 1-9. doi: $10.1093 /$ nar/gkt1223

Hilge, M., Gloor, S. M., Rypniewski, W., Sauer, O., Heightman, T. D., Zimmermann, W., et al. (1998). High-resolution native and complex structures of thermostable $\beta$-mannanase from Thermomonospora fusca - substrate specificity in glycosyl hydrolase family 5. Structure 6, 1433-1444. doi: 10.1016/ S0969-2126(98)00142-7

Huang, J. W., Chen, C. C., Huang, C. H., Huang, T. Y., Wu, T. H., Cheng, Y. S., et al. (2014). Improving the specific activity of $\beta$-mannanase from Aspergillus niger BK01 by structure-based rational design. Biochim. Biophys. Acta, Proteins Proteomics 1844, 663-669. doi: 10.1016/j.bbapap.2014.01.011

Jana, U. K., Suryawanshi, R. K., Prajapati, B. P., and Kango, N. (2020). Prebiotic mannooligosaccharides: synthesis, characterization and bioactive properties. Food Chem. 342:128328. doi: 10.1016/j.foodchem.2020. 128328

Jiang, Z., Wei, Y., Li, D., Li, L., Chai, P., and Kusakabe, I. (2006). High-level production, purification and characterization of a thermostable $\beta$-mannanase from the newly isolated Bacillus subtilis WY34. Carbohydr. Polym. 66, 88-96. doi: $10.1016 /$ j.carbpol.2006.02.030

Kaira, G. S., Panwar, D., and Kapoor, M. (2016). Recombinant endo-mannanase (ManB-1601) production using agro-industrial residues: development of economical medium and application in oil extraction from copra. Bioresour. Technol. 209, 220-227. doi: 10.1016/j.biortech.2016.02.133

Katrolia, P., Yan, Q., Zhang, P., Zhou, P., Yang, S., and Jiang, Z. (2013). Gene cloning and enzymatic characterization of an alkali-tolerant endo-1,4- $\beta$ mannanase from Rhizomucor miehei. J. Agric. Food Chem. 61, 394-401. doi: $10.1021 / \mathrm{jf} 303319 \mathrm{~h}$

Katrolia, P., Zhou, P., Zhang, P., Yan, Q., Li, Y., Jiang, Z., et al. (2012). High level expression of a novel $\beta$-mannanase from Chaetomium sp. exhibiting efficient mannan hydrolysis. Carbohydr. Polym. 87, 480-490. doi: 10.1016/j. carbpol.2011.08.008

Kelley, L. A., Mezulis, S., Yates, C. M., Wass, M. N., and Sternberg, M. J. (2016). The Phyre2 web portal for protein modeling, prediction and analysis. Nat. Protoc. 10, 845-858. doi: 10.1038/nprot.2015.053

Kim, D. Y., Ham, S. J., Lee, H. J., Cho, H. Y., Kim, J. H., Kim, Y. J., et al. (2011). Cloning and characterization of a modular GH5 $\beta$-1,4-mannanase with high specific activity from the fibrolytic bacterium Cellulosimicrobium sp. strain HY-13. Bioresour. Technol. 102, 9185-9192. doi: 10.1016/j. biortech.2011.06.073

La Rosa, S. L., Leth, M. L., Michalak, L., Hansen, M. E., Pudlo, N. A., Glowacki, R., et al. (2019). The human gut Firmicute Roseburia intestinalis is a primary degrader of dietary $\beta$-mannans. Nat. Commun. 10, 1-14. doi: 10.1038/s41467-019-08812-y

Larsson, A. M., Anderson, L., Xu, B., Muñoz, I. G., Usón, I., Janson, J. C., et al. (2006). Three-dimensional crystal structure and enzymic characterization of $\beta$-mannanase Man5A from blue mussel Mytilus edulis. J. Mol. Biol. 357, 1500-1510. doi: 10.1016/j.jmb.2006.01.044

Liu, S., Cui, T., and Song, Y. (2020a). Expression, homology modeling and enzymatic characterization of a new $\beta$-mannanase belonging to glycoside hydrolase family 1 from Enterobacter aerogenes B19. Microb. Cell Factories 19, 1-19. doi: 10.1186/s12934-020-01399-w

Liu, H. X., Gong, J. S., Li, H., Lu, Z. M., Li, H., Qian, J. Y., et al. (2015). Biochemical characterization and cloning of an endo-1,4- $\beta$-mannanase from Bacillus subtilis YH12 with unusually broad substrate profile. Process Biochem. 50, 712-721. doi: 10.1016/j.procbio.2015.02.011
Liu, Z., Ning, C., Yuan, M., Yang, S., Wei, X., Xiao, M., et al. (2020b). Highlevel expression of a thermophilic and acidophilic $\beta$-mannanase from Aspergillus kawachii IFO 4308 with significant potential in mannooligosaccharide preparation. Bioresour. Technol. 295:122257. doi: 10.1016/j.biortech.2019.122257

Lv, J., Chen, Y., Pei, H., Yang, W., Li, Z., Dong, B., et al. (2013). Cloning, expression, and characterization of $\beta$-mannanase from Bacillus subtilis MAFIC-S11 in Pichia pastoris. Appl. Biochem. Biotechnol. 169, 2326-2340. doi: 10.1007/s12010-013-0156-8

Miller, G. L. (1959). Use of dinitrosalicylic acid reagent for determination of reducing sugar. Anal. Chem. 31, 426-428. doi: 10.1021/ac60147a030

Ratananikom, K., Choengpanya, K., Tongtubtim, N., Charoenrat, T., Withers, S. G., and Kongsaeree, P. T. (2013). Mutational analysis in the glycone binding pocket of Dalbergia cochinchinensis $\beta$-glucosidase to increase catalytic efficiency toward mannosides. Carbohydr. Res. 373, 35-41. doi: 10.1016/j. carres.2012.10.018

Sinitsyna, O. A., Fedorova, E. A., Vakar, I. M., Kondratieva, E. G., Rozhkova, A. M., Sokolova, L. M., et al. (2008). Isolation and characterization of extracellular $\alpha$-galactosidases from Penicillium canescens. Biochemist 73, 97-106. doi: $10.1007 /$ s10541-008-1015-z

Srivastava, P. K., and Kapoor, M. (2017). Production, properties, and applications of endo- $\beta$-mannanases. Biotechnol. Adv. 35, 1-19. doi: 10.1016/j. biotechadv.2016.11.001

Sternke, M., Tripp, K. W., and Barrick, D. (2019). Consensus sequence design as a general strategy to create hyperstable, biologically active proteins. Proc. Natl. Acad. Sci. U. S. A. 166, 11275-11284. doi: 10.1073/pnas.1816707116

Takeda, N., Hirasawa, K., Uchimura, K., Nogi, Y., Hatada, Y., Akita, M., et al. (2004). Alkaline mannanase from a novel species of Alkaliphilic bacillus. J. Appl. Glycosci. 51, 229-236. doi: 10.5458/jag.51.229

van Zyl, W. H., Rose, S. H., Trollope, K., and Görgens, J. F. (2010). Fungal $\beta$-mannanases: Mannan hydrolysis, heterologous production and biotechnological applications. Process Biochem. 45, 1203-1213. doi: 10.1016/j. procbio.2010.05.011

Vijayalaxmi, S., Prakash, P., Jayalakshmi, S. K., Mulimani, V. H., and Sreeramulu, K. (2013). Production of extremely alkaliphilic, halotolerent, detergent, and thermostable mannanase by the free and immobilized cells of Bacillus halodurans PPKS-2. Purification and characterization. Appl. Biochem. Biotechnol. 171, 382-395. doi: 10.1007/s12010-013-0333-9

Zhang, M., Chen, X. L., Zhang, Z. H., Sun, C. Y., Chen, L. L., He, H. L., et al. (2009). Purification and functional characterization of endo- $\beta$-mannanase MAN5 and its application in oligosaccharide production from konjac flour. Appl. Microbiol. Biotechnol. 83, 865-873. doi: 10.1007/s00253-009-1920-0

Zhang, Y., Ju, J., Peng, H., Gao, F., Zhou, C., Zeng, Y., et al. (2008). Biochemical and structural characterization of the intracellular mannanase AaManA of Alicyclobacillus acidocaldarius reveals a novel glycoside hydrolase family belonging to clan GH-A. J. Biol. Chem. 283, 31551-31558. doi: 10.1074/ jbc.M803409200

Zhang, W., Liu, Z., Zhou, S., Mou, H., and Zhang, R. (2019). Cloning and expression of a $\beta$-mannanase gene from Bacillus sp. MK-2 and its directed evolution by random mutagenesis. Enzym. Microb. Technol. 124, 70-78. doi: 10.1016/j.enzmictec.2019.02.003

Zhang, R., Song, Z., Wu, Q., Zhou, J., Li, J., Mu, Y., et al. (2016). A novel surfactant-, NaCl-, and protease-tolerant $\beta$-mannanase from Bacillus sp. HJ14. Folia Microbiol. 61, 233-242. doi: 10.1007/s12223-015-0430-y

Zhao, J., Shi, P., Luo, H., Yang, P., Zhao, H., Bai, Y., et al. (2010). An acidophilic and acid-stable $\beta$-mannanase from Phialophora sp. P13 with high mannan hydrolysis activity under simulated gastric conditions. J. Agric. Food Chem. 58, 3184-3190. doi: 10.1021/jf904367r

Zheng, C., Li, F., Hao, Z., and Liu, T. (2018). Effects of adding mannan oligosaccharides on digestibility and metabolism of nutrients, ruminal fermentation parameters, immunity, and antioxidant capacity of sheep. $J$. Anim. Sci. 96, 284-292. doi: 10.1093/jas/skx040

Conflict of Interest: The authors declare that the research was conducted in the absence of any commercial or financial relationships that could be construed as a potential conflict of interest.

Publisher's Note: All claims expressed in this article are solely those of the authors and do not necessarily represent those of their affiliated organizations, or those of the publisher, the editors and the reviewers. Any product that may 
be evaluated in this article, or claim that may be made by its manufacturer, is not guaranteed or endorsed by the publisher.

Copyright (C) 2021 Liang, Zhan, Yuan, Cao, Zhu, Mou and Liu. This is an open-access article distributed under the terms of the Creative Commons Attribution License
(CC BY). The use, distribution or reproduction in other forums is permitted, provided the original author(s) and the copyright owner(s) are credited and that the original publication in this journal is cited, in accordance with accepted academic practice. No use, distribution or reproduction is permitted which does not comply with these terms. 